\title{
Cardiac CT Improves Outcomes in Stable Coronary Heart Disease: Results of Recent Clinical Trials
}

\author{
Michelle C. Williams $^{1} \cdot$ Alastair Moss $^{1} \cdot$ Edward Nicol $^{2} \cdot$ David E. Newby $^{1}$
}

Published online: 25 March 2017

(C) The Author(s) 2017. This article is published with open access at Springerlink.com

\begin{abstract}
Purpose of Review The purpose of this study was to review the recent randomised controlled trials of coronary computed tomography angiography (CCTA) for patients with stable coronary artery disease.

Recent Findings The initial results and subsequent papers from the SCOT-HEART (Scottish COmputed Tomography of the HEART) and PROMISE (PROspective Multicentre Imaging Study for Evaluation of chest pain) trials have shown that CCTA is a safe and appropriate addition to standard care or alternative to functional testing. The SCOT-HEART study showed that CCTA changes diagnoses, improves diagnostic certainty, changes management, leads to more appropriate use of invasive coronary angiography, and reduces fatal and nonfatal myocardial infarction. A meta-analysis of the four randomised controlled trials showed that CCTA leads to a major reduction in myocardial infarction in patients with stable chest pain.

Summary CCTA is now an established technique for the assessment of coronary artery disease. Recent 'test and treat' randomised controlled trials have shown that CCTA guided changes in management can improve clinical outcomes.
\end{abstract}

This article is a part of the Topical Collection on Cardiac Computed Tomography

Michelle C. Williams

michelle.williams@ed.ac.uk

1 University of Edinburgh/British Heart Foundation Centre for Cardiovascular Science, Chancellor's Building, 49 Little France Crescent, Edinburgh EH164SB, UK

2 Royal Brompton and Harefield NHS Trust Departments of Cardiology and Radiology, London, UK
Keywords Computed tomography $\cdot$ Chest pain $\cdot$ Angina . Coronary heart disease

$\begin{array}{ll}\text { Abbreviations } \\ \text { CCTA } & \text { Coronary computed tomography angiography } \\ \text { CI } & \text { Confidence interval } \\ \text { ETT } & \text { Exercise tollerance test } \\ \text { HR } & \text { Hazard ratio } \\ \text { ICA } & \text { Invasive coronary angiography } \\ \text { mSv } & \text { Millisievert } \\ \text { MPS } & \text { Myocardial perfusion single photon emission } \\ \text { OR } & \text { Odds ratio } \\ \text { RACPC } & \text { Rapid access chest pain clinic } \\ \text { RR } & \text { Relative risk }\end{array}$

\section{Introduction}

Coronary computed tomography angiography (CCTA) is now an established technique for the assessment of patients with suspected coronary artery disease (CAD). It has an excellent diagnostic accuracy for the identification of CAD, with a high negative predictive value [1]. Large-scale registry studies have shown the prognostic utility of CCTA in the identification of both obstructive disease and non-obstructive atherosclerotic plaque. However, recent clinical studies have moved beyond the assessment of diagnostic accuracy or registry studies. This review discusses the outcome-based research that has established the role of CCTA in the assessment of patients with suspected coronary heart disease.

A normal CCTA is associated with a good prognosis in large registry studies of patients with suspected CAD [2-4]. Both the presence and the extent of obstructive CAD were associated with a worsening prognosis in the COronary $\mathrm{CT}$ 
Angiography EvaluatioN For Clinical Outcomes: An InteRnational Multicenter (CONFIRM) registry [5]. In addition, the extent of non-obstructive coronary artery atherosclerotic plaque was a predictor of mortality in several registry studies $[4,6,7]$ and the use of statin therapy at baseline was associated with reduced mortality for patients with nonobstructive CAD in the CONFIRM study [6]. The lack of randomisation in registry studies means that there is major confounding by indication, and that they cannot determine the clinical utility of CCTA or the effect of treatment decisions based on CCTA results. More recently, several large 'test and treat' randomised controlled trials have been performed to address these issues, including the PROMISE and SCOTHEART studies.

\section{PROMISE}

The PROMISE (PROspective Multicentre Imaging Study for Evaluation of chest pain) trial recruited 10,003 symptomatic stable outpatients who were due to undergo non-invasive investigation for suspected CAD $[8 \bullet \bullet$. Participants were randomised to undergo either anatomical assessment with CCTA or functional testing with exercise electrocardiography, stress echocardiography or radionucleotide perfusion imaging (Table 1).

The mean age of the participants was 61 years, $53 \%$ were female and the pre-test probability of obstructive CAD was $53 \%$. Over one quarter of patients $(27 \%)$ presented with a primary symptom other than chest pain, such as breathlessness or fatigue. The characterisation of chest pain was typical angina for $12 \%$, atypical angina for $78 \%$ and non-anginal chest pain for $11 \%$ (Table 2).
The primary outcome of the PROMISE study was a composite of all-cause mortality, myocardial infarction, hospitalisation for unstable angina and major complications of cardiovascular procedures or diagnostic testing. At 12 months of follow-up, the risk of death or non-fatal myocardial infarction was lower in the CCTA group than in the functional imaging group (hazard ratio (HR) $0.66,95 \%$ confidence interval (CI) $0.44-1.00, P=0.049)$. However, at 25 months of follow-up, there was no difference in the primary outcome between the two groups (events 3.3 vs $3.0 \%$, HR $1.04,95 \%$ CI $0.83-1.29, P=0.75$ ). Thus, PROMISE showed that CCTA is a safe alternative to functional testing in a lowrisk population with similar outcomes in both groups after 2 years of follow-up.

\section{SCOT-HEART}

The SCOT-HEART (Scottish COmputed Tomography of the HEART) trial randomised 4146 outpatients with suspected angina due to CAD to standard care or standard care plus CCTA [9]. Participants were recruited from cardiology outpatient rapid access chest pain clinics (RACPC) and $47 \%$ of all eligible patients were recruited, including patients with atrial fibrillation, high calcium score and high body mass index $[10 \bullet \cdot$.

The mean age of participants was 57 years, $44 \%$ were female and the pre-test probability of obstructive coronary heart disease was $47 \%$. The presence of typical angina was higher in the SCOT-HEART trial as compared to the PROMISE trial (35 vs $12 \%$ of participants). Atypical angina was the presenting complaint in $24 \%$ of patients (cf. $78 \%$ in PROMISE) and $41 \%$ (cf. 11\%) had non-anginal chest pain (Table 2).
Table 1 Study design of the four randomised studies of CCTA

\begin{tabular}{|c|c|c|c|c|}
\hline & PROMISE & SCOT-HEART & CAPP & Min et al. \\
\hline $\begin{array}{l}\text { Recruiting } \\
\text { centres }\end{array}$ & 193 & 12 & 1 & 1 \\
\hline $\begin{array}{l}\text { Study } \\
\text { groups }\end{array}$ & $\begin{array}{l}\text { CCTA vs functional testing } \\
\text { (ETT, stress echo or } \\
\text { radionucleotide } \\
\text { perfusion imaging) }\end{array}$ & $\begin{array}{l}\text { CCTA and standard care vs } \\
\text { standard care alone }\end{array}$ & $\begin{array}{l}\text { CCTA vs } \\
\text { ETT }\end{array}$ & CCTA vs MPS \\
\hline $\begin{array}{l}\text { Primary } \\
\text { endpoint }\end{array}$ & $\begin{array}{l}\text { Composite of all-cause } \\
\text { mortality, myocardial } \\
\text { infarction, } \\
\text { hospitalisation for } \\
\text { unstable angina, and } \\
\text { major complications of } \\
\text { cardiovascular } \\
\text { procedures or diagnostic } \\
\text { testing }\end{array}$ & $\begin{array}{l}\text { Proportion of patients } \\
\text { diagnosed with angina } \\
\text { pectoris secondary to } \\
\text { coronary heart disease at } \\
6 \text { weeks }\end{array}$ & $\begin{array}{l}\text { Difference in } \\
\text { symptoms } \\
\text { from } \\
\text { baseline to } \\
3 \text { months }\end{array}$ & $\begin{array}{c}\text { Angina-specific } \\
\text { health status }\end{array}$ \\
\hline $\begin{array}{l}\text { Follow-up } \\
\text { duration } \\
\text { (months) }\end{array}$ & 25 & 20 & 12 & 55 days \\
\hline
\end{tabular}

ETT exercise electrocardiography, echo echocardiography, MPS myocardial perfusion single photon emission 
Table 2 Demographic details of patients recruited into the four randomised studies of CCTA

\begin{tabular}{|c|c|c|c|c|c|}
\hline & & PROMISE & SCOT-HEART & CAPP & Min et al. \\
\hline \multicolumn{2}{|l|}{ Number } & 10,003 & 4146 & 448 & 180 \\
\hline \multicolumn{2}{|l|}{ Age (years) } & 61 & 57 & 59 & 56,59 \\
\hline \multicolumn{2}{|l|}{ Female $(\%)$} & 53 & 44 & 45 & 44 \\
\hline \multicolumn{2}{|c|}{ Pre-test probability (\%) } & 53 & 47 & 45,48 & - \\
\hline \multirow[t]{3}{*}{ Chest pain (\%) } & Typical angina & 12 & 35 & 34 & 32 \\
\hline & Atypical angina & 78 & 24 & 8 & 23 \\
\hline & Non-anginal chest pain & 11 & 41 & 67 & 27 \\
\hline
\end{tabular}

The primary endpoint of the SCOT-HEART trial was the certainty of the diagnosis angina pectoris secondary to significant CAD at 6 weeks (Table 1). At 6 weeks, the diagnosis was changed in $23 \%$ of patients undergoing CCTA compared to $1 \%$ in the standard care group $(p<0.0001)$. CCTA improved the certainty of the diagnosis for both the presence of CAD and the diagnosis of angina due to (CAD) (RR 2.56, 95\% CI 2.33-2.79, $P<0.0001$ and RR $1.79,95 \%$ CI $1.79,1.62-1.96$, $P<0.001)$. CCTA increased the frequency of the diagnosis of CAD (relative risk (RR) 1.09, 95\% CI 1.02-1.17, $P=0.0172$ ), but tended to decrease the frequency of the diagnosis of angina due to significant CAD (RR 0.93, 95\% CI 0.85-1.02, $P=0.1289$ ).

At 1.7 years of follow-up, the CCTA group had a $38 \%$ lower rate of fatal and non-fatal myocardial infarction as compared to the control group, but this difference did not quite reach statistical significance ( 26 vs 42 , HR $0.62,95 \%$ CI $0.38-1.01, P=0.0527)[10 \bullet \cdot$. The overall event rate was low, similar to the PROMISE study, occurring in just $2 \%$ of participants. However, in a post hoc landmark analysis censored to the median time of treatment alteration (50 days), there was a 50\% reduction in fatal and non-fatal myocardial infarction in the CCTA group (17 vs 34 , HR $0.50,95 \%$ CI $0.28-0.88, P=0.020)[11 \bullet \bullet]$.

\section{Other Studies and Meta-analysis}

There are two other smaller randomised controlled trials which have recently assessed CCTA in patients with stable chest pain: the CAPP trial [12•] and a study by Min et al. [13•].

The CAPP trial randomised 500 patients with stable chest pain who were referred to a RACPC for assessment [12•]. Patients were randomised to either undergo exercise stress electrocardiogram (ETT) or CCTA (Table 1). The mean age was 59 years, $45 \%$ were female, and the pre-test probability of significant CAD was $45 \%$ in the ETT group and $48 \%$ in the CCTA group $(P=0.34)$ (Table 2$)$. The primary endpoint was the difference in symptoms from baseline to 3 months between the two groups, assessed using the Seattle Angina Questionnaire. They identified no difference in major adverse cardiac events between the ETT and CCTA groups.
The study by Min et al. randomised 180 patients with stable chest pain from cardiology outpatient clinics to undergo CCTA or myocardial perfusion single photon emission CT (MPS). [13•] (Table 1) The mean age was 56 years for the CCTA group and 59 years for the MPS group $(P=0.04)$, and $44 \%$ were female (Table 2 ). Pre-test probability was not provided but $32 \%$ had typical angina, $23 \%$ atypical angina and $27 \%$ non-anginal chest pain. The primary endpoint was the "angina-specific health status". No patients had a myocardial infarction or died in either group during the follow-up of 55 days.

A meta-analysis has combined the primary results of PROMISE, SCOT-HEART, CAPP and the study by Min et al. [14•]. It identified that compared to standard care, the use of CCTA was associated with a reduction in the annual rate of myocardial infarction (rate ratio $0.69,95 \%$ CI 0.49 $0.98, P=0.038$ ), but there was no difference in all-cause mortality [14•]. This $31 \%$ relative risk reduction in myocardial infarction occurred with CCTA despite the relatively low rate of events in the individual studies over a median of 2 years of follow-up.

\section{Effect of CCTA on Downstream Investigations}

In the SCOT-HEART trial, CCTA led to a change in the planned investigations in $15 \%$ of participants, compared to $1 \%$ in the standard care group $(P<0.0001)$ [10 • ]. For some participants, planned investigations were cancelled, whilst for others, new investigations were organised, primarily invasive coronary angiography (ICA). Overall, the rates of ICA were similar between groups in the SCOT-HEART study (409 vs $401, P=0.451)$. In the study by Min et al., there were also similar rates of ICA between the CCTA and the MPS groups [13•]. However, in the PROMISE study, there was an increase in the number of patients undergoing ICA in the CCTA group compared to the functional imaging group (12.2 vs $8.1 \%$ at 90 days). In both the PROMISE and SCOT-HEART, there was a reduction in the proportion of patients with normal ICA $[8 \bullet \bullet, 11 \bullet$ ]. In SCOT-HEART, normal or nonobstructive CAD was identified at invasive coronary angiography in $29 \%$ of patients in the CT group compared to $41 \%$ of 
patients in the standard care group. Normal coronary arteries at invasive coronary angiography were identified in SCOTHEART in $6.6 \%$ of patients in the CT group compared to $19.6 \%$ in the standard care group. In PROMISE, normal or non-obstructive CAD was identified at invasive coronary angiography in $28 \%$ of patients in the CT group compared to $53 \%$ in the control group. This shows that CCTA can be used to select appropriately patients for ICA and can reduce the number performed in patients with normal coronary arteries.

\section{Medical Treatment}

In the SCOT-HEART study, treatment was changed in $23 \%$ of patients in the CCTA group compared to $5 \%$ in the standard care group $(P<0.0001)$. This included an increase in the use of preventative therapies (such as statins, Aspirin and ACE inhibitors) and decrease in the use of anti-anginal therapies $[10 \bullet, 11 \bullet \cdot$. Min et al. also demonstrated that patients in the CCTA arm had a subsequent increased use of aspirin and statins [13•]. CCTA can identify non-obstructive CAD which other investigations may not identify. It is therefore not surprising, nor a new finding, that CCTA is associated with an increased use of preventative medications in such patients [15]. However, a major strength of CCTA is its negative predictive value and therefore the cessation of unnecessary medications in patients with normal coronary arteries is also an important outcome after CCTA.

\section{Revascularisation}

In the PROMISE trial, there was an increase in the numbers of patients going on to have revascularisation after invasive coronary angiography in the CCTA group (6.2 vs $3.2 \%$, $P<0.001$ ) [8・日. In the SCOT-HEART trial, there was also a statistically non-significant trend towards an increased proportion of revascularisation in the CCTA group (11.2 vs 9.7\%, $P=0.0611$ ) $[10 \bullet \cdot$. Therefore, CCTA can be used to more appropriately select patients who require further invasive investigation and treatment.

\section{Cost Analysis}

In both the SCOT-HEART and the PROMISE trials, there was a small increase in cost in the CCTA group. In the PROMISE study, the mean cost difference at 90 days was \$254 (95\% confidence interval $-\$ 634$ to $\$ 906$ ) [16], and in the SCOTHEART study, the difference was $\$ 462$ (95\% confidence interval $\$ 303$ to $\$ 621$ ) at 6 months [11••]. In the PROMISE study the cost difference was due to the increased use of ICA and revascularisation in the CCTA group. However, in the SCOT-HEART study the difference was attributed to the cost of CCTA itself, as the rate of ICA was not statistically different between groups $[11 \bullet \cdot$. The cost of CCTA technology continues to fall and therefore this small difference in cost between investigation strategies is likely to continue to decrease in the future.

\section{Symptoms}

In SCOT-HEART, PROMISE and CAPP trials, symptoms improved in both groups of patients indicating general satisfaction after attendance at the RACPC or cardiology outpatient clinic $[10 \bullet, 12,17]$. In the SCOT-HEART trial, there was no difference in symptoms at 6 week between CCTA and standard care groups [10••]. In the PROMISE trial, there was no difference in symptoms over 2 years of follow-up between the CCTA group or functional imaging group [17]. In the study by Min et al., there was no difference in angina symptoms between groups at 55 days [13•]. However, in the CAPP study, there was a larger improvement in angina symptoms in the CCTA group compared to the ETT group at 3 and 12 months [12•]. This suggests that there may be improved management and patient satisfaction after CCTA as compared to ETT. Whilst CCTA undoubtedly improves diagnosis and allows the optimisation of treatment for patients, CCTA findings can also provide potential uncertainty and anxiety, particularly for those patients who are subsequently recommended to start life-long preventative treatments for nonobstructive CAD. Therefore, it is important to consider potential patient anxiety when communicating the results of the CCTA.

\section{Radiation Dose}

In the PROMISE trial, the overall radiation exposure was higher in the CCTA group (mean $12 \mathrm{mSv}$ (milliseverts) vs $10.1 \mathrm{mSv}, P<0.001)$. However, as $33 \%$ of patients in the functional testing group did not have any radiation exposure at all, and therefore, the median cumulative radiation exposure per patient was lower in the CCTA group (10.0 vs $11 \mathrm{mSv})$. In the SCOT-HEART trial, the median radiation dose for CCTA and non-contrast coronary artery calcium score was 4.1 (interquartile range 3.0-5.6) $\mathrm{mSv}$. More than one third of the radiation exposure in the SCOT-HEART trial was attributed to the coronary artery calcium score. The additional benefit of performing a non-contrast scan for calcium scoring in patients who are undergoing CCTA is low, and indeed, in many cases, this additional examination is not required. The mean radiation dose in the CCTA group of the CAPP trial was $5.37 \mathrm{mSv}$. In the study by Min et al., the CCTA group had a significantly lower radiation dose than the MPS group (7.4 vs $13.3 \mathrm{mSv}$, $P<0.001)$. CCTA can now be performed at a low radiation dose for patients with a range of heart rates and body size (Fig. 1). 

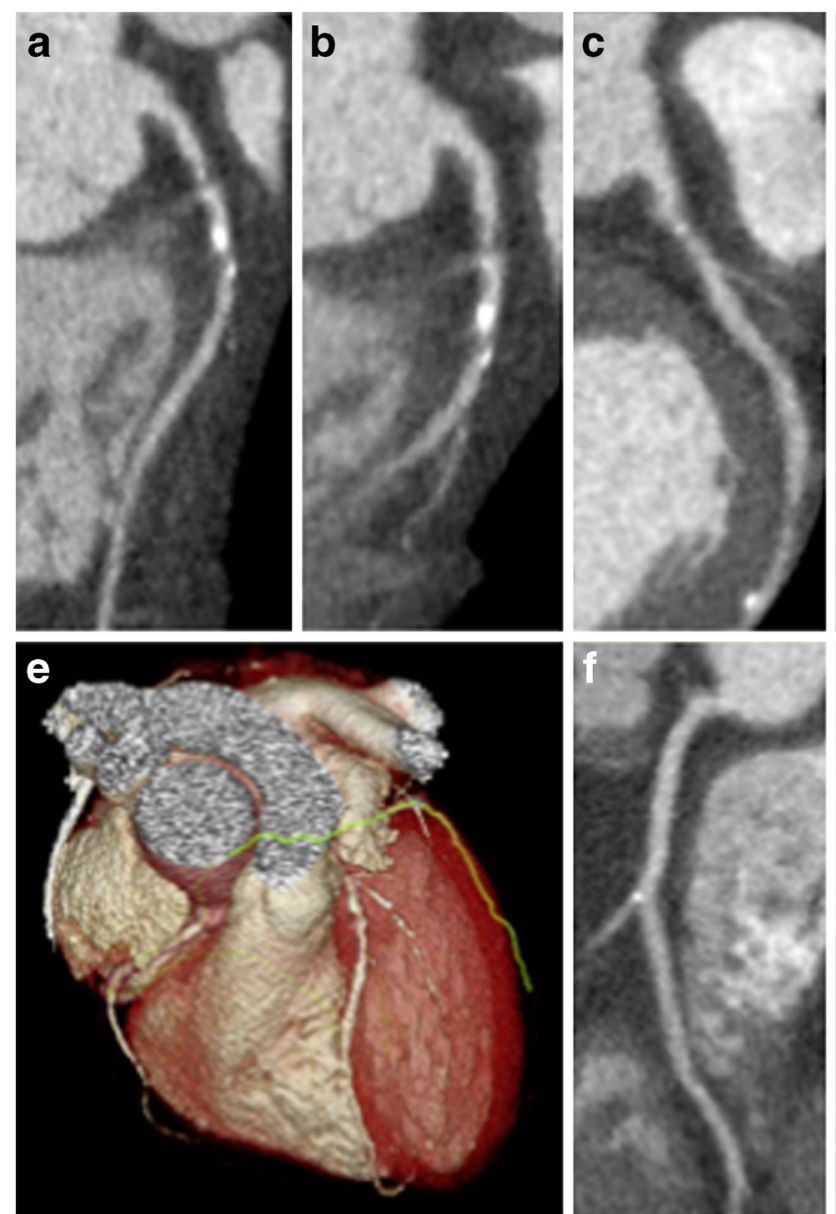
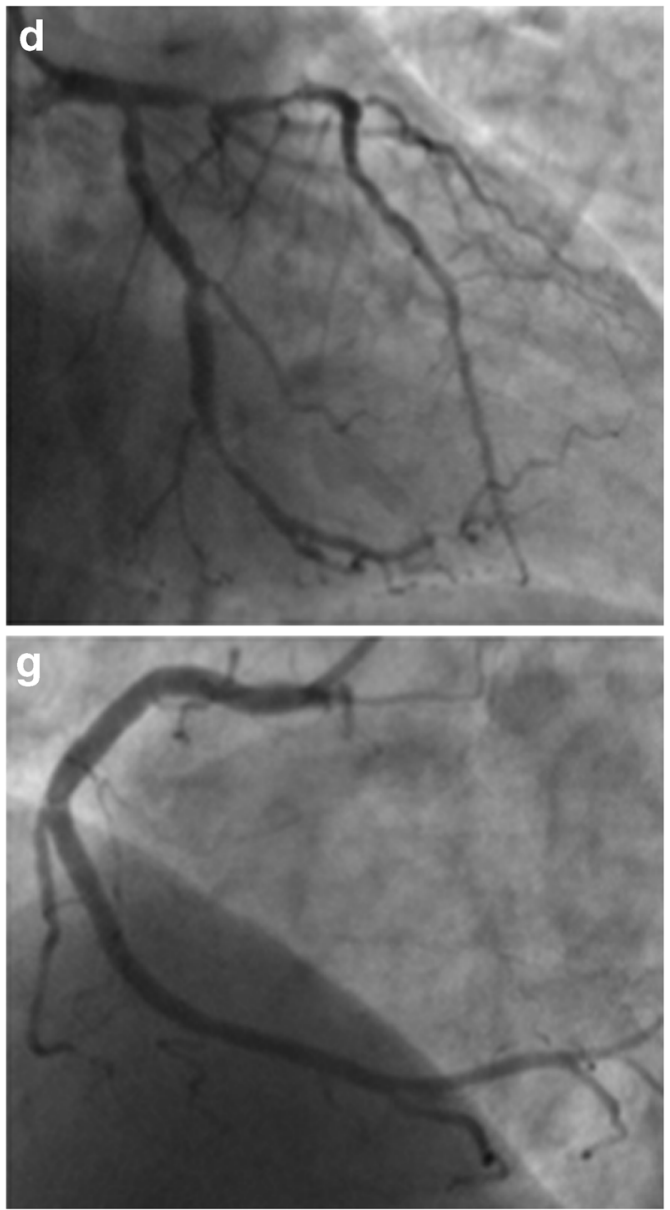

Fig. 1 An example of low radiation dose CCTA with comparison to invasive coronary angiography from the SCOT-HEART study. This 60year-old male patient with no previous history of cardiovascular disease and no cardiovascular risk factors presented with chest pain. CCTA identified severe disease in the left anterior descending coronary artery (a), first diagonal (b) and circumflex artery (c) which was confirmed on

\section{Plaque Characterisation}

In addition to assessing stenosis severity, CCTA can assess the constituents and morphology of atherosclerotic plaques. Motoyama et al. identified that the presence of low attenuation plaque, positive remodelling and spotty calcification were associated with an increased risk of acute coronary syndrome [18]. A meta-analysis of subsequent studies found a significantly higher risk of acute coronary syndromes in patients who had high-risk plaque (odds ratio (OR) $12.1,95 \%$ CI 5.24-28.1, $P=0.0001$ ) [19]. However, the use of these plaque markers in randomised outcome-based research studies have not yet been assessed.

\section{Functional Assessment}

Cardiac CT can assess myocardial perfusion using static or dynamic techniques with good diagnostic accuracy compared to other imaging modalities [20]. Computational fluid invasive coronary angiograph (d). Mild non-obstructive disease was identified in the right coronary artery (f, g). e Shows a threedimensional reconstruction of the heart from the CT. The patient underwent revascularisation. The total dose length product for CCTA and calcium scoring $\mathrm{CT}$ was $358 \mathrm{mGy} \mathrm{cm}$ ( $5 \mathrm{mSv}$ using the $0.014 \mathrm{mSv} / \mathrm{mGy} \mathrm{cm}$ conversion factor)

dynamic models can estimate pressure and flow within the coronary arteries. These estimates can be used to calculate non-invasive fractional flow reserve (FFR). The use of noninvasive FFR based on CCTA images may reduce the rate of normal invasive coronary angiograms, lower costs reduce radiation exposure, improved quality of life and improve the detection of lesions causing ischaemia [21-24].

\section{Conclusion}

CCTA is a safe diagnostic test that can be performed at a low radiation dose and is now widely available. Recent clinical trials have established the role of CCTA in the assessment of patients with suspected CAD. The use of CCTA not only changes the diagnosis but it also alters management that ultimately reduces the future risk of fatal and non-fatal myocardial infarction. National guidelines, such as the UK NICE guidelines, have recently changed to incorporate CCTA as 
the first-line test in stable chest pain (discussed by Moss et al. in another paper in this issue) and other international guidelines are likely to follow suit in time.

\section{Compliance with Ethical Standards}

Conflict of Interest David E Newby reports grants and personal fees from Toshiba during the conduct of study.

The other three authors declare that they have no conflict of interest.

Human and Animal Rights and Informed Consent This article does not contain any studies with human or animal subjects performed by any of the authors.

Open Access This article is distributed under the terms of the Creative Commons Attribution 4.0 International License (http:// creativecommons.org/licenses/by/4.0/), which permits unrestricted use, distribution, and reproduction in any medium, provided you give appropriate credit to the original author(s) and the source, provide a link to the Creative Commons license, and indicate if changes were made.

\section{References}

Papers of particular interest, published recently, have been highlighted as:

- Of importance

•- Of major importance

1. Miller JM, Rochitte CE, Dewey M, et al. Diagnostic performance of coronary angiography by 64-row CT. N Engl J Med. 2008;359: 2324-36.

2. Andreini D, Pontone G, Mushtaq S, et al. A long-term prognostic value of coronary CT angiography in suspected coronary artery disease. J Am Coll Cardiol Img. 2012;5:690-701.

3. Min JK, Shaw LJ, Devereux RB, Okin PM, Weinsaft JW, Russo DJ, Lippolis NJ, Berman DS, Callister TQ. Prognostic value of multidetector coronary computed tomographic angiography for prediction of all-cause mortality. J Am Coll Cardiol. 2007;50:1161-70.

4. Hadamitzky M, Taubert S, Deseive S, Byrne RA, Martinoff S, Schömig A, Hausleiter J. Prognostic value of coronary computed tomography angiography during 5 years of follow-up in patients with suspected coronary artery disease. Eur Heart J. 2013a; doi:10. 1093/eurheartj/eht293.

5. Hadamitzky M, Achenbach S, Al-Mallah M, et al. Optimized prognostic score for coronary computed tomographic angiography: results from the CONFIRM registry (COronary CT Angiography EvaluatioN For Clinical Outcomes: An InteRnational Multicenter Registry). J Am Coll Cardiol. 2013b;62:468-76.

6. Chow BJW, Small G, Yam Y, et al. Prognostic and therapeutic implications of statin and aspirin therapy in individuals with nonobstructive coronary artery disease: results from the CONFIRM (Coronary CT aAngiography Evaluation For ClinicalOutcomes: An International Multicenter Registry) registry. Arterioscler Thromb Vasc Biol. 2015;35:981-9.

7. Bittencourt MS, Hulten E, Ghoshhajra B, et al. Prognostic value of nonobstructive and obstructive coronary artery disease detected by coronary computed tomography angiography to identify cardiovascular events. Circulation: Cardiovascular Imaging. 2014;7:282-91.

8.• Douglas PS, Hoffmann U, Patel MR, et al. Outcomes of anatomical versus functional testing for coronary artery disease. $\mathrm{N}$ Engl J Med. 2015a;372:1291-300. Results of the PROMISE study
9. Newby DE, Williams MC, Flapan AD, et al. Role of multidetector computed tomography in the diagnosis and management of patients attending the rapid access chest pain clinic, the Scottish computed tomography of the heart (SCOT-HEART) trial: study protocol for randomized controlled trial. Trials. 2012;13:184.

$10 . \bullet$ SCOT-HEART investigators. CT coronary angiography in patients with suspected angina due to coronary heart disease (SCOTHEART): an open-label, parallel-group, multicentre trial. Lancet. 2015;385:2383-91. Results of the SCOT-HEART study

11.• Williams MC, Hunter A, Shah ASV, et al. Use of coronary computed tomographic angiography to guide management of patients with coronary disease. J Am Coll Cardiol. 2016;67:1759-68. Post hoc landmark analysis from the SCOT-HEART study showing a $50 \%$ reduction in fatal and non-fatal myocardial infarction

12. McKavanagh P, Lusk L, Ball PA, et al. A comparison of cardiac computerized tomography and exercise stress electrocardiogram test for the investigation of stable chest pain: the clinical results of the CAPP randomized prospective trial. European Heart Journal Cardiovascular Imaging. 2015;16:441-8. Results of the CAPP study

13. Min JK, Koduru S, Dunning AM, et al. Coronary CT angiography versus myocardial perfusion imaging for near-term quality of life, cost and radiation exposure: a prospective multicenter randomized pilot trial. J Cardiovasc Comput Tomogr. 2012;6:274-83. Results of the study by Min et al

14. Bittencourt MS, Hulten EA, Murthy VL, Cheezum M, Rochitte CE, Di Carli MF, Blankstein R. Clinical outcomes after evaluation of stable chest pain by coronary computed tomographic angiography versus usual care: a meta-analysis. Circulation: Cardiovascular Imaging. 2016;9:e004419. Meta-analysis of studies of clinical outcomes after evaluation of stable chest pain

15. Nicol ED, Stirrup J, Leatham E, Roughton M, Underwood SR, Padley SPG, Rubens MB. Clinical management and short-term cost - 64-slice MDCT vs. myocardial perfusion scintigraphy. Int J Cardiol. 2010;144:248-50.

16. Mark DB, Federspiel JJ, Cowper PA, et al. Economic outcomes with anatomical versus functional diagnostic testing for coronary artery disease. Ann Intern Med. 2016a;165:94-102.

17. Mark DB, Anstrom KJ, Sheng S, et al. Quality-of-life outcomes with anatomic versus functional diagnostic testing strategies in symptomatic patients with suspected coronary artery disease: results from the PROMISE randomized trial. Circulation. 2016b;133:1995-2007.

18. Motoyama S, Ito H, Sarai M, et al. Plaque characterization by coronary computed tomography angiography and the likelihood of acute coronary events in mid-term follow-up. J Am Coll Cardiol. 2015;66:337-46.

19. Thomsen C, Abdulla J. Characteristics of high-risk coronary plaques identified by computed tomographic angiography and associated prognosis: a systematic review and meta-analysis. European Heart Journal - Cardiovascular Imaging. 2016;17:120-9.

20. Williams MC, Newby DE. CT myocardial perfusion imaging: current status and future directions. Clin Radiol. 2016;71:739-49.

21. Douglas PS, Pontone G, Hlatky MA, et al. Clinical outcomes of fractional flow reserve by computed tomographic angiographyguided diagnostic strategies vs. usual care in patients with suspected coronary artery disease: the prospective longitudinal trial of FFRCT: outcome and resource impacts study. Eur Heart J. 2015b;36:3359-67.

22. Gaur S, Øvrehus KA, Dey D, et al. Coronary plaque quantification and fractional flow reserve by coronary computed tomography angiography identify ischaemia-causing lesions. Eur Heart J. 2016;37:1220-7.

23. Bilbey N, Blanke P, Naoum C, Arepalli CD, Nørgaard BL, Leipsic J. Potential impact of clinical use of noninvasive FFRCT on radiation dose exposure and downstream clinical event rate. Clin Imaging. 2016;40:1055-60.

24. Hlatky MA, De Bruyne B, Pontone G, et al. Quality of life and economic outcomes of assessing fractional flow reserve with computed tomography angiography: the PLATFORM study. J Am Coll Cardiol. 2015;66:2315-23. 